\title{
The Academic Significance and Value of The Principles in Xiangji Operation
}

\author{
Xingmei Du \\ Yunnan University \\ Qingde Chen \\ Yunnan University
}

The book The Principles in Xiangji (Interphase) Operation, written by Yang Tingshuo and published in 1995, is a major landmark in the research works of economic anthropology and ecological anthropology in China. Reading the book evokes a lot of feelings and thoughts of the reader. We respect Yang Tingshuo as an academic expert and he takes us as his brothers. The deepest feelings and thoughts come from his personal charisma.

Yang Tingshuo was born in 1942 in a big family with 10 siblings in Guiyang. Though leading a poor life, the brothers and sisters have inherited family traditions and excelled in their respective fields. Most of them are senior scholars in medicine, steel chemical, photographic film, anthropology/ethnology, agricultural machinery, and post and telecommunications network. Their gatherings are more like academic salons. Their discussion topics are related to knowledge of various disciplines, and even research activities. Since his youth, he was used to of discourses about knowledge of many disciplines, which made him crave for knowledge and laid a strong foundation for a broader academic vision. In 1963, he was enrolled in the Chinese Department of Guizhou Education University. During his college years, he saw the Cultural Revolution in China. Later, he worked as a teacher in a middle school. When China ushered in a period of reform and opening up, the 40-year-old scholar became the first postgraduate student after China instituted degree education system. In 1979, he was enrolled in Yunnan University where he found an opportunity to learn from Mr. Jiang Yingliang. There he started learning normative academic education of anthropology/ethnology. He was much enthusiastic to pursue academics with strong commitment. In 1982, Yang Tingshuo obtained master's degree and then started teaching in Guizhou Minzu University. Though suffering from serious eye disease and being almost blind, he had strong faith. He had been dedicated to academics over the past 30-plus years. He is noted for his meticulous scholarship and sincerity toward people. Taking things seriously and personally, he always leads undergraduates in field study; guides them in thesis writing; and discusses on research methods with them. Like an elder brother, he shows care and offers help to his students. In 1986, when Guizhou Federation of Literary and Art Circles opened a training course of Guizhou ethnic study, Yang Tingshuo was invited to act as the lecturer of anthropology/ethnology. The academic activity caused certain blames and setbacks in his life. But, he has no regrets and still sticks to his academic conscience, and is unchanged in guiding and supporting younger scholars. Many young people cared and guided by him have become leading researchers in Guiyang, Sichuan, Hunan, and even Fujian and Xiamen in the field of anthropology/ethnology. Although being an old man of 60 years, Yang Tingshuo is still offering comfort 
to his academic predecessors' souls in paradise with his real actions. As a famous economic anthropologist in China, he has been partaking effectively in solving the national economic problems. (Tian and Luo 2013)

Another thought is the reflection over the definition of responsibilities of scholars, and immature thinking over the value and orientation of academic research. Nowadays, chasing "hot topics" seems to be a fashion in the research of humanistic and social sciences. When people take such a phenomenon for granted, we should identify some hidden crises. The research of humanistic and social sciences can be classified into three categories: first, basic theoretical research, which aims at defining the base points and limitations of different theoretical systems, differentiating the truth and falsity of different theoretical viewpoints, and serving as the footstone for human to expand knowledge and enhance cognition; second, history research, which uses experience as the footstone, analyzes past events and facts, and offers reflective enlightenment to the real society, reflecting the profound meaning of Benedetto Croce's opinion "All history is contemporary history"; third, research in realistic problems, whose basic purpose is to discuss on and question current established facts, trends, and tendencies, seeking to offer constructive comments or thinking from different positions and perspectives. However, under the fashion flag of "hot spots research", the first two kinds of research have both been underestimated or neglected undermining the overall foundation of research efforts. Even more unfortunate is that a large number of such researches have betrayed the basic purpose and turned out to be monotonous, only appearing as the explanation, cheer or support for some established facts. Such researches cannot effectively resolve real problems, nor enrich academic learning. Such researches are rootless and ephemeral. Furthermore, it can be seen in hotspots research that differences on research points and perspectives even lead to sharply different research results.

Since the inception of the reform and opening up, the issue of China's ethnic economy has always been a hotspot for 30 years, but, some high-profile slogans and titles have faded out of sight. By contrast, Yang Tingshuo's book The Principle in Xiangji Operation which came out in 1995 is still enlightening, full of theoretical value, and worth of discussion. Out of concerns over the hotspot issues in China's ethnic economy, the book was written with a theoretical and deliberative mind and exits as one of the most important early works written by a Chinese scholar featuring systematic and theoretical analysis on the principles of economic anthropology. The book puts forward the economic subjectivity of various ethnic groups (Yang 1995). In fact, as early as the beginning of the 20th century, Yang Tingshuo emphasized the view that the culture of Southwest China deviates from the culture of center China(Yang 1991), implying that people understand themselves by understanding others which is underlined in anthropology. (Chen 2001)

In the name of the book, "xiang" is an ancient Chinese character, tracing back to The Book of Songs and Buddhology. It is widely used in modern philosophy, physics, and other subjects. Thus, it is endowed with rich academic meanings. In his book Critique of Pure Reason, Immanuel Kant classified research objects expressed by concepts and people's judgment on "appearance of an object" into four basic categories, namely quantity, quality, relation, and appearance. At such a meaning level, the use of "Xiangji" fully embodies the deep understanding of the author on the theoretical standpoints of economic anthropology and the discipline spirit.

The introduction of the book offers a brief overview of the context of economic anthropology in foreign countries. It offered a window of broader vision for China's then fledgling economic anthropology research 20 years ago. In the book, the three culture-themed articles show the strong academic background of the author on cultural anthropology. Amid the then researches in ethnic economy hot topics, the book reveals the rich background and unique perspectives of cultural anthropology. Particularly, the proposal and description of the concept "ethnic habitat" is enlightening and instructive. It clearly points out that ecological environment is a prerequisite and foundation for establishment and operation of all economic systems. The rest parts contain development theory, background theory, strength theory, policy theory, and counter-measure theory. Targeting at the then real major issues and problems, the book presents theoretical analysis at multiple levels. For the Chinese society in the recent 30 -odd years, some problems have become things of the past, such as the comments on the merits and 
demerits of planned economy. Yet, it is exactly the theoretical research base of the author that provides a strong theoretical support to the analysis of real problems, and brings landmark significance to the book in understanding the development of China's economic anthropology. The expansive theoretical vision and extensive multi-discipline knowledge of the author enabled him to pass on the focus of the spiritual struggle and theoretical appeal of economic anthropology: the discipline value of economic anthropology is to guide people ceaselessly in fully understanding the real interests and special habitats of different ethnic groups, and their development appeals amid the global economy. The author believes that any forms of economic activities are the organic components of ethnic culture, and that economy is never an isolated system, but a link of overall cultural development. Economy is within the culture sea. Different economic behaviors and consequences are subject to the guidance of certain mainstream cultural values. The mainstream cultural values of different ethnic groups cannot replace each other, nor can be imposed on others. In this book, a great highlight is to use economic factor analysis to explain the efforts of the historical and cultural phenomena of different ethnic groups; emphasize the importance of the narrative of different ethnic groups themselves; and stress on the revolution of different social systems and their different appearances in different cultures. Some scholars call it the theoretical model of "interphase management" (Luo2014).

Based on theoretical background, the correlation analysis on culture, economy, and environment has produced greater depth in the author's independent thinking. On the back of his another book Ethnic Culture and Habitat, contents of this book were further expanded and it gained a broader academic space (Yang 1995). In recent years, with Yang Tingshuo as a leader, a series of research results represented by Introduction to Ecological Anthropology, The foundation of Mankind, and Introduction to Local Ecological Knowledge, have come up as visible flags in the basic theoretical research in ecological anthropology. Independent thinking and strong commitment are probably the source of power driving the 60 -year-old Yang Tingshuo in ceaseless working. Hearing that the book has been revised and will be re-published, I have this article for it. I also expect Yang Tingshuo, who always brings enlightening and unique perspectives, would offer more academic thoughts and surprises.

\section{REFERENCES}

Chen, Q. (2001). Economic Anthropology. People's Publishing House.

Kant, I. (1998). The Critique of Pure Reason. Cambridge University Press.

Luo, K., \& Tian, G. (2014). On the practice and theoretical contribution of Localization in China of Economic Anthropology. Journal of Minzu University of China (Philosophy and Social Sciences Edition).

Tian, G., \& Luo, K. (2013). Economic Anthropology. Yinchuan, Ningxia People's Publishing House. Yang, T., \& Luo, K. (1992). Southwest and Central Plains. Yunnan Education Press.

Yang, T. (1995). Principles in Xiangji Operation: Theories and Practiceson Economic activities across Ethnic Groups.Guizhou people's Publishing House.

Yang, T., Luo, K., \& Pan, S. (1995). Ethnic Culture and Habitat. Guizhou people's Publishing House. 